\title{
Molecular cloning, sequence analysis and functional characterization of the gene cluster for biosynthesis of K-252a and its analogs $\dagger$
}

\author{
Hsien-Tai Chiu,* Yi-Lin Chen, Chien-Yu Chen, Chyn Jin, Meng-Na Lee \\ and Yu-Chin Lin
}

Received 19th March 2009, Accepted 24th June 2009

First published as an Advance Article on the web 4th August 2009

DOI: $10.1039 / b 905293 c$

\begin{abstract}
Among the indolocarbazole alkaloids of antitumor antibiotics, K-252a represents a structurally unique indolocarbazole glycoside and exhibits potent neuroprotective and broad anticancer activities. K-252a consists of K-252c and the unusual dihydrostreptose moiety, linked together with oxidative and glycosidic $\mathrm{C}-\mathrm{N}$ bonds. Herein, we reported a complete sequence of an approximately $45 \mathrm{~kb}$ genomic fragment harboring the gene cluster for the biosynthesis of indolocarbazole alkaloids in Nocardiopsis sp. K-252 (NRRL15532). The sequence of 35 open reading frames discovered several new, critical genes, hence shedding new light on biosynthesis, resistance and regulation of K-252a and its analogs. To functionally characterize the gene cluster in vitro and in enzyme level, a multigene expression cassette containing the K-252c biosynthetic genes was constructed and successfully overexpressed in Escherichia coli to yield soluble proteins for cell-free tandem enzymatic assays. Consequently, the heterologous expression with soluble NokA and NokB led to in vitro production of chromopyrrolic acid (CPA), thereby providing functional evidence for K-252c biosynthesis. Moreover, a facile production of CPA in culture broth was successfully accomplished by using an in vivo biotransformation of L-tryptophan with $E$. coli harboring the gene cassette. Importantly, by sequence analysis and the functional characterization here and in the companion paper, biosynthetic pathways leading to formation of K-252a and its analogs were hence proposed. Together, the results provide critical information and materials useful for combinatorial biosynthesis of K-252a and its analogs for therapeutic applications.
\end{abstract}

\section{Introduction}

The family of indolocarbazole natural products has been a valuable source of lead compounds with potential therapeutic applications in the treatment of cancer and neurodegenerative disorders (Fig. 1). ${ }^{1-5}$ Nocardiopsis sp. K-252 (Nonomuraea longicatena, NRRL15532) produces indolocarbazole alkaloids of antitumor antibiotics, among which K-252a represents a structurally unique indolocarbazole glycoside exhibiting neuroprotective activity and displaying potent cytotoxic activities against numerous cancer cells by inhibiting protein kinases. ${ }^{6-8}$ Structurally distinct in the family, K-252a is characterized by the dihydrostreptose moiety and two $\mathrm{C}-\mathrm{N}$ covalent linkages, one of which is generated by a catalytic action of $\mathrm{N}$-glycosyltransferase (N-Gtf) and the other by an oxidative coupling enzyme. ${ }^{9}$ To date, the exact biosynthetic pathways and regulations leading to formation of $\mathrm{K}-252 \mathrm{a}$ and its analogs

Department of Biological Science and Technology, National Chiao Tung University, 75 Po-Ai Street, Hsinchu 300, Taiwan. E-mail:Chiu@mail.nctu.edu.tw; Fax:+886-3-5719605;

Tel: + 886-3-5131595

$\dagger$ Electronic supplementary information (ESI) available: Experimental procedures for cloning, expression and purification of His-tagged proteins of NokABCD; summary of the discrepancies between nok and ink genetic loci; degenerate PCR results; PCR primers; NMR data. See DOI: $10.1039 /$ b905293c in Nocardiopsis sp. K-252 remains still obscure. And the enzymes for the pathways have not been characterized in vitro to reveal actual functional roles and substrate specificity. In particular, there is a serious lack of information on the enzymes responsible for the formation of the modified dihydrostreptose moiety of K-252a. Thus far, many of the studies in deoxysugar biosynthesis are limited to the biogenesis of pyranoses. ${ }^{10}$ Such information can be of great value for useful applications of the enzymes in expanding the structural diversity of bioactive natural product glycosides by incorporating various special furanoses like the dihydrostreptose. Moreover, some microorganisms, such as Nocardiopsis strains, were found to be capable of producing multiple analogs of indolocarbazole compounds, ${ }^{3,11,12}$ raising an interesting question with regards to whether or not the microorganisms may, through proper regulation, utilize a single N-Gtf gene or a single set of K-252c biosynthesis genes for their biosynthesis. Resolution of the above interesting issues must rely on sequence information and functional characterization of the genes involved in the biosynthesis and regulation of K-252a and its analogs, which would be very useful for combinatorial biosynthesis of K-252a analogs for therapeutic applications.

In light of the above important facts and prospects, we constructed a fosmid genomic DNA library of Nocardiopsis $s p$. K-252 and therein cloned and identified the gene cluster for the biosynthesis of the indolocarbazole compounds. We now 

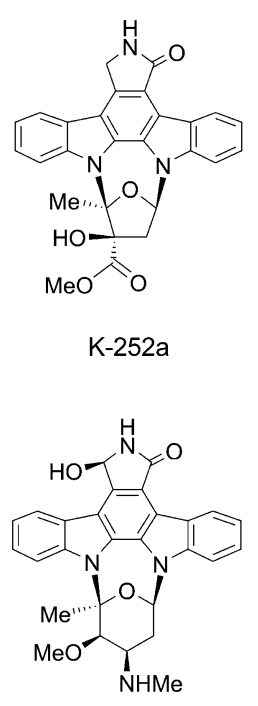

UCN-01

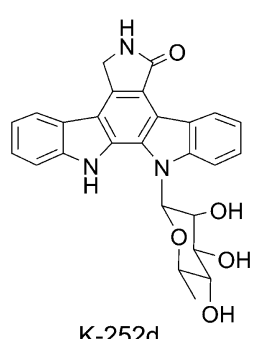

K-252d

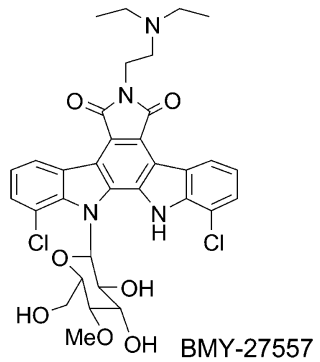

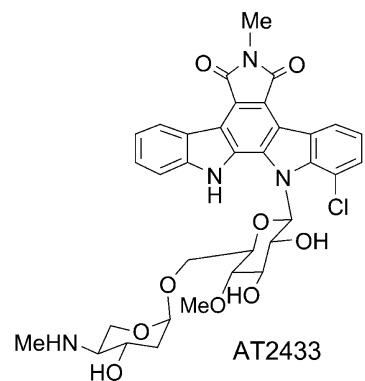

$\mathrm{HO}$

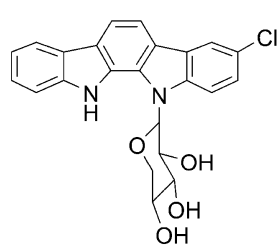

Tjipanazole F2

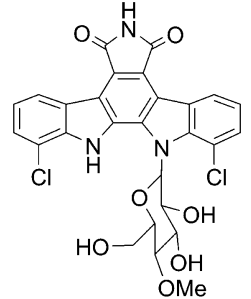

Rebeccamycin

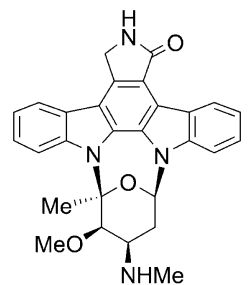

Staurosporine

Fig. 1 Representative members (or derivatives) of the indolocarbazole family of natural products.

report the complete $45 \mathrm{~kb}$ genomic sequence harboring the gene cluster. Our bioinformatic analysis of the gene cluster has allowed us to functionally deduce the embedded genes and propose biosynthetic pathways leading to formation of the indolocarbazole compounds, especially that of the special dihydrostreptose moiety of K-252a. Most notably, by in vitro functional characterization here and in the following paper, we proposed the gene cluster served not only for biosynthesis of K-252a but also for those of its analogs. In addition, construction and overexpression in E. coli of the $\mathrm{K}-252 \mathrm{c}$ biosynthetic gene cassette were successfully achieved in this study, whereas the heterologous expression of the gene cassette led to both in vitro and in vivo functional production of chromopyrrolic acid (CPA) involved in K-252c biosynthesis.

\section{Results and discussion}

\section{Construction of the Nocardiopsis sp. K-252 fosmid library}

To identify the biosynthetic gene cluster, we constructed a fosmid genomic DNA library of Nocardiopsis sp. K-252 by use of a CopyControl fosmid library production kit (Epicentre). Genomic DNA of Nocardiopsis sp. K-252 was randomly sheared, size-selected between $30 \mathrm{~kb}$ and $70 \mathrm{~kb}$, and then ligated into the $E$. coli fosmid vector pCC1FOS. The resulting ligation products were packaged into $\lambda$-phage (Gigapack kit, Stratagene), followed by transfection into E. coli EPI300 (Epicentre). As a result, the genomic library was successfully constructed with a total of 5856 fosmid clones, whereas the average sizes of genomic DNA fragments were ca. $35 \mathrm{~kb}$ per clone.

\section{Cloning of the biosynthetic gene cluster for K-252a and its analogs}

As shown in Scheme 1, we proposed the biosynthesis of the modified dihydrostreptose in K-252a utilized the common deoxysugar biosynthetic pathway involving
NDP-4-keto-6-deoxy-glucose (KDG) as a key biosynthetic intermediate. ${ }^{13}$ In the presence of nucleotide triphosphate, KDG can be synthesized from glucose-1-phosphate by catalytic actions of NDP-glucose synthase and NDP-glucose 4,6-dehydratase. ${ }^{14,15}$ Hence, two sets of degenerate primers AG4-AG5 and P1-P2, respectively, were utilized as probes to screen the fosmid library, where the primers were derived from conserved sequences of the homologous genes coding for these two enzymes from various Streptomyces species producing glycosylated secondary metabolites. ${ }^{16,17}$ Using Nocardiopsis sp. $\mathrm{K}-252$ genomic DNA as a template, polymerase chain reaction (PCR) amplifications with the probes yielded DNA fragments of $300 \mathrm{bp}$ and $480 \mathrm{bp}$ (Fig. S1, ESI $\dagger$ ), respectively, confirmed to partially code for the enzymes. Designed based on the coding DNA sequences, specific primer pairs were subsequently applied to screen the Nocardiopsis sp. K-252 fosmid library by PCR, therefore leading to identification of three overlapping fosmid clones, pJC3B5, pJC40D7 and pJC28B7 (see Materials and methods). Together, the three fosmid clones constituted a genomic DNA fragment of $c a .57 \mathrm{~kb}$, from which a $45 \mathrm{~kb}$ sequence contig was subsequently obtained by DNA sequencing to cover the entire gene cluster for the biosynthesis of the indolocarbazole compounds, presumably K-252a and its analogs, in Nocardiopsis sp. K-252.

\section{Organization of genes in the $\mathbf{4 5} \mathbf{k b}$ genomic sequence harboring the biosynthetic gene cluster}

Sequence analysis of the $45 \mathrm{~kb}$ genomic sequence revealed 35 open reading frames (ORFs) as shown in Fig. 2, whereas its detailed information (e.g., annotation and ORF prediction) was deposited in GenBank. ${ }^{18}$ In Table 1 are also summarized their deduced functions and related information. As in our $45 \mathrm{~kb}$ contig, nok $A B C D$ genes, encoding enzymatic assembly of K-252c 1 from L-tryptophan 2 (Scheme 1), shared a high degree of similarity to those in reb, sta and atm gene clusters (see also gene cluster comparison as in Fig. 3). ${ }^{9,19,20}$ Within the nok gene cluster was found nokJ, a cytochrome P450 gene, 


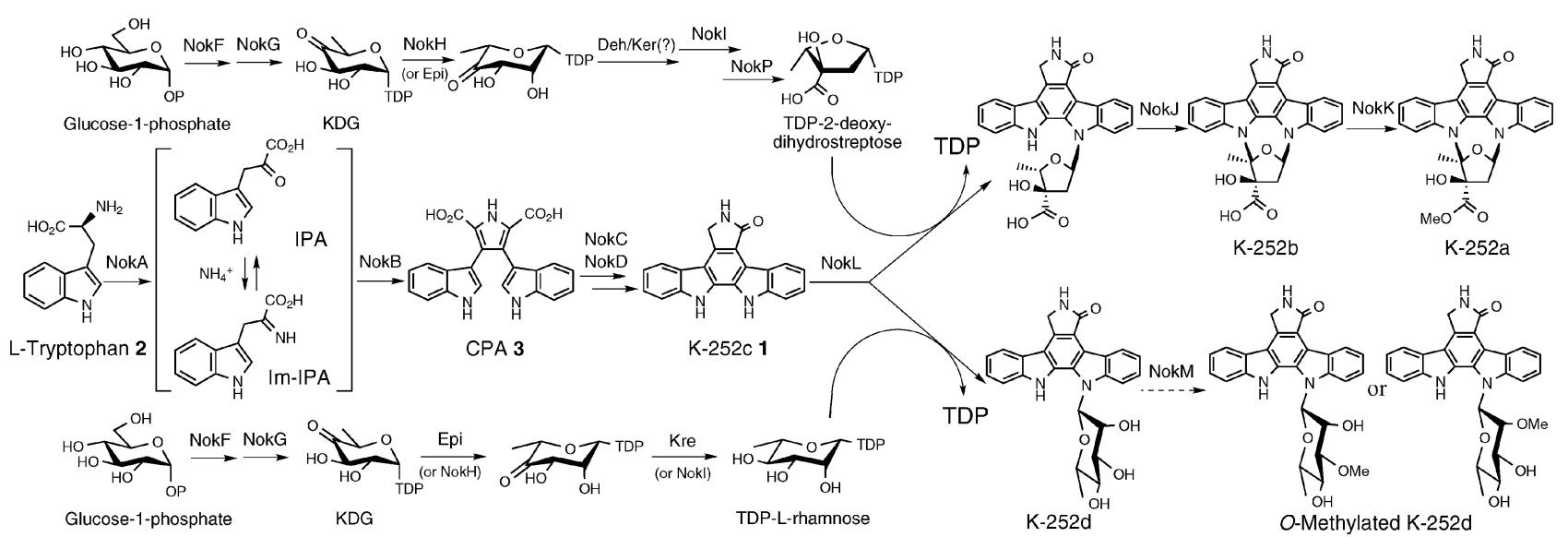

Scheme 1 The proposed biosynthetic pathway for biosyntheses of indolocarbazole metabolites in Nocardiopsis sp. K-252.
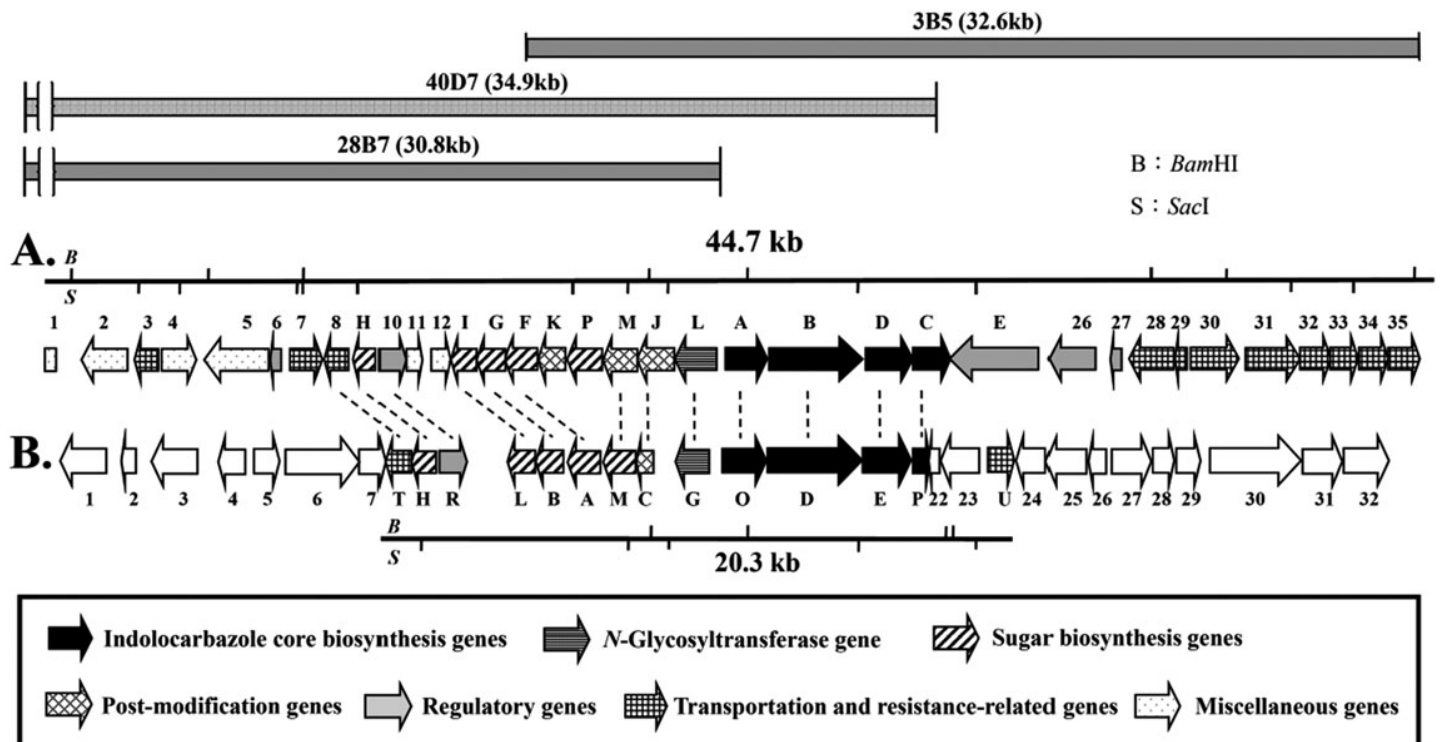

Fig. 2 (A) The genetic map of our $45 \mathrm{~kb}$ genomic fragment harboring the nok gene cluster for biosyntheses of K-252a and its analogs and (B) comparison with the ink genetic locus reported by Kim et al. ${ }^{35}$ where only $20.3 \mathrm{~kb}$ (as shown in lower restriction map) was actually deposited in GenBank under accession number DQ399653. The dotted lines indicate the matched ORF with the same proposed function. Sketch indicates putative or known functions, and arrows represent the direction of transcription of ORFs.

speculated to be responsible for the oxidative $\mathrm{C}-\mathrm{N}$ linkage. Like $\operatorname{staN}$ for staurosporine biosynthesis, ${ }^{21}$ the nokJ gene resembles in amino acid sequence $(45.1 \%$ similarity and $30.7 \%$ identity) the eryF gene responsible for hydroxylation of 6-deoxy-erythronolide B, one of early steps in erythromycin biosynthesis in Saccharopolyspora erythraea. ${ }^{22}$ Sequence analysis of NokJ revealed the highly conserved heme-binding domain (GXXXCXG), K-helix and oxygen binding region $\left(\mathrm{O}_{2}-\mathrm{BR}\right),{ }^{22-24}$ also preserved in StaN and EryF, as shown in Fig. 4. Very interestingly, NokJ, unlike StaN, shared the same alaine in the $\mathrm{O}_{2}-\mathrm{BR}$ of EryF for dioxygen activation. Above findings may suggest NokJ adapt a similar catalytic mechanism as EryF but, however, give a distinct catalytic consequence in form of $\mathrm{C}-\mathrm{N}$ oxidative coupling.

As shown in Scheme 1, the nokFGHIP genes presumably involved in biosynthesis of NDP-2-deoxy-dihydrostreptose (NDP-dStp) were found to be embedded within the cluster.
As generally observed in deoxysugar biosynthesis, the 2-deoxygenation required for NDP-dStp biosynthesis may utilize a catalytic action of NDP-sugar 2,3-dehydratase (Deh). ${ }^{25-27}$ Interestingly, our experiment showed that the deh gene, coding for Deh, was found to be outside of the gene cluster in the genome. $^{28}$ The 2-deoxygenation may occur after the 3,5-epimerization presumably catalyzed by NokH.

Most interestingly, in our gene cluster the nokP gene was also found to be required to work with nokI to complete the biosynthesis of NDP-dStp. The nokI gene highly resembled, in amino acid sequence (56\% identity and 63\% similarity), the dTDP-dihydrostreptose synthase gene $(s t r L)$ in streptomycin biosynthesis. $^{29}$ The nokP gene coded for a cytochrome p450 hydroxylase/oxidase, highly resembling the homologous enzymes participating in oxidative modification of secondary metabolites, such as leinamycin (Streptomyces atroolivaceus), saframycin A (Streptomyces lavendulae) and pradimicin 
Table 1 Deduced functions for genes in the $45 \mathrm{~kb}$ genomic sequence ${ }^{a}$ harboring the nok gene cluster for biosyntheses of K-252a and its analogs

\begin{tabular}{|c|c|c|c|c|c|c|c|c|}
\hline ORF & Protein & Start/stop & $\begin{array}{l}\text { Size } \\
\text { (a.a.) }\end{array}$ & Homolog; accession number & $\begin{array}{l}\mathrm{ID} / \mathrm{SM} \\
(\%)^{b}\end{array}$ & $r e b^{c}$ & $s t a^{c}$ & $\operatorname{atm}^{c}$ \\
\hline$\overline{1^{d}}$ & NokX & $e$ & - & $\begin{array}{l}\text { LysR-protein transcriptional regulator; } \\
\text { EDX21545 }\end{array}$ & $43 / 58$ & - & - & - \\
\hline $2^{d}$ & & ATG/TGA & 504 & Amidase; BAC74980 & $60 / 68$ & - & - & - \\
\hline $3^{d}$ & & ATG/TGA & 282 & Integral membrane protein; CAM0193 & $63 / 77$ & - & - & - \\
\hline $4^{d}$ & & GTG/TGA & 395 & Threonine synthase homolog; CAM00339 & $40 / 49$ & - & - & - \\
\hline $5^{d}$ & & GTG/TAA & 799 & ATP-dependent RNA helicase; BAC73942 & $59 / 67$ & - & - & - \\
\hline $6^{d}$ & & ATG/TGA & 105 & Regulatory protein; CAD55454 & $51 / 66$ & - & - & - \\
\hline $7^{d}$ & & ATG/TGA & 387 & $\begin{array}{l}\text { Transmembrane efflux protein from the } \\
\text { major facilitator superfamily; CAG14958 }\end{array}$ & $43 / 61$ & $r e b T$ & - & atmI \\
\hline 8 & NokN $(\operatorname{InkT})^{f}$ & GTG/TGA & 277 & $\begin{array}{l}\text { Putative integral membrane lipid kinase; } \\
\text { BAG23064 }\end{array}$ & $56 / 72$ & - & - & - \\
\hline 9 & NokH $^{g}(\operatorname{InkH})$ & ATG/TGA & 268 & $\begin{array}{l}\text { Nucleoside-diphosphate-sugar epimerase; } \\
\text { ABZ94902 }\end{array}$ & $40 / 57$ & - & staE & - \\
\hline 10 & NokO (InkR) & ATG/TGA & 300 & $\begin{array}{l}\text { AraC family transcriptional regulator; } \\
\text { BAG17958 }\end{array}$ & $64 / 76$ & - & - & - \\
\hline 11 & NokQ ${ }^{h}$ & ATG/TGA & 172 & Secreted protein; EDX26326 & $42 / 53$ & - & - & - \\
\hline 12 & NokR ${ }^{h}$ & ATG/TGA & 215 & Lipoate-protein ligase B; ABD11507 & $57 / 68$ & - & - & - \\
\hline 13 & NokI (InkL) & ATG/TGA & 282 & $\begin{array}{l}\text { dTDP-dihydrostreptose synthase; } \\
\text { CAA44443 }\end{array}$ & $56 / 63$ & - & - & - \\
\hline 14 & NokG (InkB) & ATG/TGA & 309 & dTDP-glucose 4,6-dehydratase; BAC55206 & $71 / 78$ & - & $s t a B$ & - \\
\hline 15 & NokF $(\operatorname{InkA})^{h}$ & GTG/TGA & 354 & $\begin{array}{l}\text { Glucose-1-phosphate thymidyltransferase; } \\
\text { BAC55207 }\end{array}$ & $72 / 83$ & - & staA & atmS7 \\
\hline $16^{d}$ & NokK & ATG/TGA & 285 & $\begin{array}{l}\text { Aklanonic acid methyl transferase; } \\
\text { AAF70111 }\end{array}$ & $35 / 47$ & - & - & - \\
\hline $17^{d}$ & NokP & ATG/TGA & 398 & Cytochrome P450 hydroxylase; AAN85514 & $44 / 58$ & - & - & - \\
\hline 18 & NokM (InkM) & GTG/TGA & 377 & Sugar O-methyl transferase; CAJ42340 & $50 / 63$ & rebM & $\operatorname{sta} M B$ & atmM \\
\hline 19 & NokJ $(\text { InkY) })^{h^{\prime}}$ & GTG/TGA & 398 & Cytochrome P450; BAC55208 & $52 / 68$ & - & - & staN \\
\hline 20 & NokL $\left(\right.$ InkG) ${ }^{h}$ & TTG/TGA & 436 & N-glycosyltransferase; BAC55209 & $57 / 70$ & $r e b G$ & $\operatorname{staG}$ & atmG \\
\hline 21 & NokA (InkO) & ATG/TGA & 486 & L-amino acid oxidase; BAC55210 & $60 / 71$ & $\mathrm{rebO}$ & $\operatorname{staO}$ & atmO \\
\hline 22 & NokB (InkD) & ATG/TGA & 1031 & Chromopyrrolic acid synthase; BAC55211 & $53 / 62$ & rebD & staD & atmD \\
\hline 23 & NokD (InkE) & ATG/TGA & 525 & Monooxygenase; BAF47693 & $61 / 71$ & $r e b C$ & staC & $\operatorname{atm} C$ \\
\hline $24^{d}$ & NokC $(\operatorname{InkP})^{i}$ & ATG/TGA & 409 & Cytochrome P-450 RebP; BAC 15753 & $54 / 64$ & rebP & staP & atmP \\
\hline $25^{d}$ & NokE & GTG/TAG & 962 & Transcriptional activator; BAC 15755 & $35 / 47$ & $r e b R$ & staR & atmR \\
\hline $26^{d}$ & NokS & GTG/TGA & $\begin{array}{l}503 \text { or } \\
725\end{array}$ & $\begin{array}{l}\text { Sensor kinase, two-component system; } \\
\text { ABG94428 }\end{array}$ & $52 / 64$ & - & - & - \\
\hline $27^{d}$ & NokT & GTG/TGA & 114 & $\begin{array}{l}\text { Response regulator receiver protein; } \\
\text { ABM } 12887\end{array}$ & $56 / 62$ & - & - & - \\
\hline $28^{d}$ & NokU & ATG/TAG & 510 & $\begin{array}{l}\text { Amino acid/metabolite permease; } \\
\text { CAD55470 }\end{array}$ & $45 / 60$ & - & - & - \\
\hline $29^{d}$ & NokV & GTG/TAA & 102 & $\begin{array}{l}\text { Putative integral membrane protein; } \\
\text { CAJ89547 }\end{array}$ & $51 / 56$ & - & - & - \\
\hline $30^{d}$ & NokW & ATG/TAA & 544 & $\begin{array}{l}\text { ABC transporter ATP-binding protein; } \\
\text { CAB40692 }\end{array}$ & $75 / 86$ & - & - & - \\
\hline $31^{d}$ & & ATG/TGA & 601 & $\begin{array}{l}\text { Putative peptide transport system secreted } \\
\text { peptide binding protein; CAM } 01499\end{array}$ & $42 / 59$ & - & - & - \\
\hline $32^{d}$ & & ATG/TGA & 348 & $\begin{array}{l}\text { Putative peptide transport system permease; } \\
\text { CAM01500 }\end{array}$ & $63 / 76$ & - & - & - \\
\hline $33^{d}$ & & GTG/TGA & 315 & $\begin{array}{l}\text { Putative peptide transport permease; } \\
\text { CAB } 37469\end{array}$ & $55 / 72$ & - & - & - \\
\hline $34^{d}$ & & ATG/TGA & 324 & $\begin{array}{l}\text { ABC transporter ATP-binding protein; } \\
\text { CAB37470 }\end{array}$ & $69 / 79$ & - & - & - \\
\hline $35^{d}$ & & ATG/TAA & 330 & $\begin{array}{l}\text { Peptide transport ATP-binding protein; } \\
\text { CAB37471 }\end{array}$ & $73 / 80$ & - & - & - \\
\hline
\end{tabular}

${ }^{a}$ Totally 35 ORFs were identified with complete sequence available in our study; translated products of some ORFs were named Nok proteins. ${ }^{b}$ ID: \% identity of amino acid sequences; SM: \% similarity of amino acid sequences. The values of identity and similarity were obtained by NCBI BLASTX analysis on protein databases. ${ }^{c}$ reb, sta and atm indicate the gene clusters of rebeccamycin, staurosporine and AT2433, respectively. (see refs. 9, 19 and 20). ${ }^{d}$ Genes lacking sequence information, not reported or scrambled in ink gene cluster. (see Table S1, ESI). ${ }^{e}$ Incomplete open reading frame (ORF). ${ }^{f}$ ( ) renders the Ink protein reported by Kim et al., see ref. $35 .{ }^{g}$ The exact function and possible involvement of NokH in K-252a biosynthesis should be experimentally determined. ${ }^{h}$ InkY (171 a.a., InkC in ink paper) is 227 a.a. shorter than NokJ; InkG (383 a.a.; 419 a.a. in ink paper) is 53 a.a. shorter than NokL; the sequence region harboring nok $Q$ and nok $R$ was not annotated in ink. (see Table S1). ${ }^{i}$ ink $A$ and inkP contain other DNA fragments.

(Actinomadura hibisca P157-2).$^{30-32}$ NokP may thus satisfy the need for the oxidative maturation of the carboxylate group in the biosynthesis of the modified dihydrostreptose in K-252a.
Based on the genetic information, two possible enzymatic pathways, path $\mathrm{A}$ and path $\mathrm{B}$, may be proposed to account for the dihydrostreptose biosynthesis, as illustrated in 


\section{nok
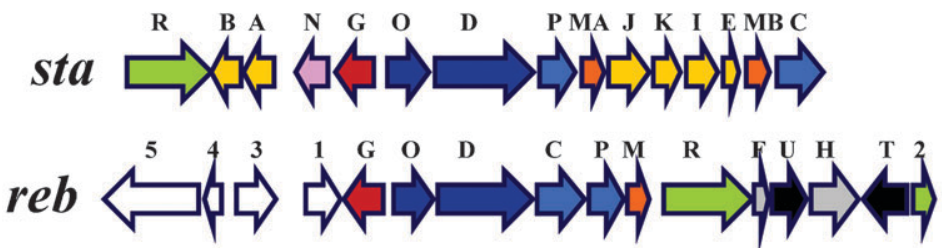
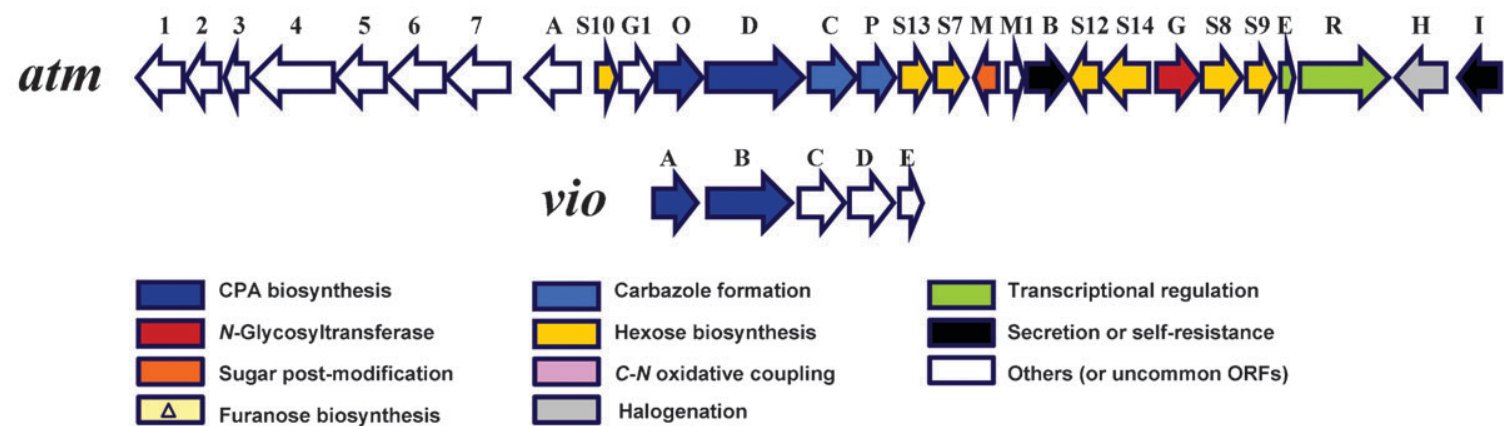

Halogenation

Fig. 3 Comparison of genetic loci responsible for the biosynthesis of K-252a (and its analogs; nok genes; accession number FJ031030), staurosporine (sta genes; accession number AB088119), rebeccamycin (reb genes; accession number AB090952), AT2433 (atm genes; accession number DQ297453) and violacein (vio genes; accession number AB032799).

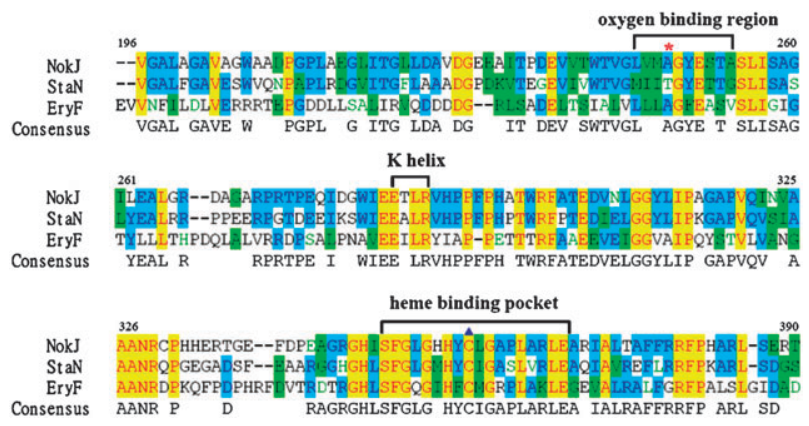

Fig. 4 Sequence alignment of the cytochrome P450 domains of NokJ with StaN and EryF. StaN, cytochrome P450 in staurosporine biosynthesis from Streptomyces $s p$. TP-A0274; ${ }^{9}$ EryF, cytochrome $\mathrm{P} 450$ in erythromycin biosynthesis from Saccharopolyspora erythraea. ${ }^{22}$ The amino acids (Ala or Thr) proposed to be involved in the $\mathrm{O}_{2}$ activation mechanism are marked with an asterisk. The conserved Cys for heme-binding is marked with closed triangle. The indicated region/pocket and helix are the conserved domains in cytochrome P450 enzymes, such as EryF and PicK (picromycin biosynthesis). ${ }^{22-24}$

Scheme 2. In path A, a presumed reductase gene, coding for NDP-sugar 3-keto-reductase (Ker), was proposed to act with deh for the formation of NDP-2-deoxy-4-keto-rhamnose (DKR), ${ }^{25-27,33,34}$ serving as a precursor for NokI and NokP for final maturation of the activated sugar. Mechanistically, a catalytic base in NokI may abstract the $\mathrm{C} 3-\mathrm{OH}$ proton, followed by 1,2-shift carbon rearrangement between $\mathrm{C} 3$ and $\mathrm{C} 4$ with concurrent protonation of the C4-keto group to give the aldehyde intermediate. After the ring contraction catalyzed by NokI, the intermediate may then be further oxidized by NokP to give NDP-dStp. In path B, NokI may directly act on the enzymatic product of Deh, and carry out the reduction at $\mathrm{C}-4$ in the presence of $\mathrm{NAD}(\mathrm{P}) \mathrm{H}$, followed by subsequent ring contraction as indicated. This pathway can be supported by previous study that StrL was proposed to possess both 4-hexulose reductase and ring contraction activities. ${ }^{36}$

Moreover, two ORFs, nokK and nokM, coding for methyltransferases were both found within the cluster. The nok $K$ gene displayed high sequence similarity to $a k n G(46.5 \%$ similarity and $33.9 \%$ identity) ${ }^{37}$ and chaI $(54.0 \%$ similarity and $39.4 \%$ identity) ${ }^{38}$ proposed to catalyze methyl esterification of the carboxylate group in biosynthesis of aclacinomycin and chartreusin, respectively. As shown in Fig. 5, NokK, ChaI and AknG shared the common motifs involved in binding of S-adenosylmethionine (SAM). However, nokM only resembles regular sugar O-methyltransferase genes generally engaged for methylation of sugar hydroxyl groups, e.g., stfMII in steffimycin biosynthesis and $\operatorname{spnI} / \operatorname{spn} K$ in spinosyn biosynthesis. $^{34,41}$ Hence, it should be evident that nokK, instead of nokM, serves as the best candidate responsible for K-252a methylation. The methyl esterification catalyzed by NokK may be a post-modification step occurring after the N-glycosylation by NokL.

In the gene cluster was found the nokE gene coding for ATP-dependent transcriptional activator of LuxR family. NokE shared a high level of sequence similarity $(45.6 \%$ similarity and $33.8 \%$ identity) to RebR in rebeccamycin biosynthesis. $^{42}$ The involvement of nokE in nok gene regulation can be supported by previous experiments that rebR-truncated mutant of the rebeccamycin-producer, Lechevalieria aerocolonigenes, failed to produce rebeccamycin or related compounds. Adjacent to nokE are nokS and nokT, encoding two-component system sensor kinase and response regulator, respectively. The homolog of highest similarity to 


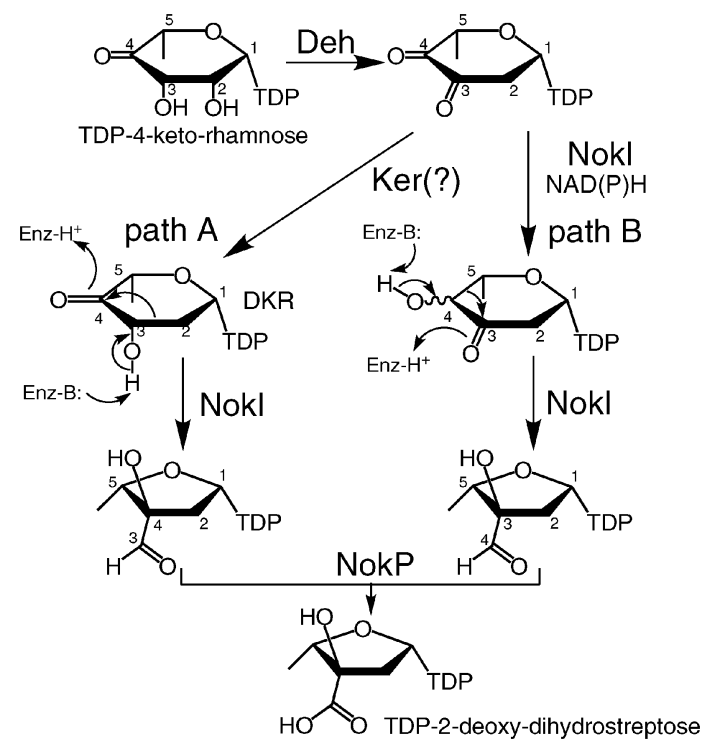

Scheme 2 Proposed enzymatic pathways for biosynthesis of TDP-2deoxy-dihydrostreptose.

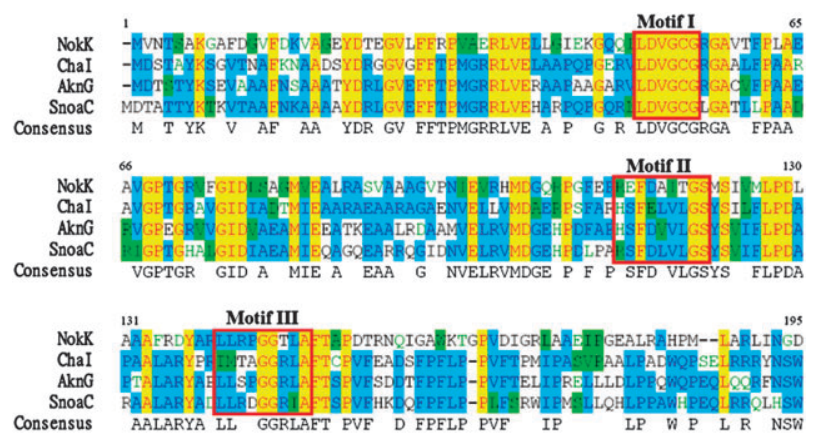

Fig. 5 Alignment of the proposed carboxylate methyltransferase (NokK) of K-252a with similar methyltransferases (MT) encompassing the SAM-dependent MT signature motifs I, II and III. ${ }^{39,40}$ ChaI, MT in chartreusin biosynthesis from Streptomyces chartreusis; AknG, MT in aclacinomycin biosynthesis from Streptomyces galilaeus; SnoaC, MT from Streptomyces pristinaespiralis.

nokS was found in Streptomyces clavuligerus producing clavulanic acid $(57.6 \% \text { identity })^{43}$ and that to nokT in Mycobacterium vanbaalenii PYR-1 capable of degrading polycyclic aromatic hydrocarbons $\left(43.8 \%\right.$ identity) ${ }^{44}$ Downstream of nokS and nokT were nokV, encoding an integral membrane protein, and nokW, encoding ABC-transporter ATP-binding protein. NokW displayed very high sequence similarity ( $>70 \%$ identity) to ATP-binding components of various $\mathrm{ABC}$-transporters in many drug-producing actinomycetes, including Streptomyces coelicolor A3(2), Streptomyces griseus and Saccharopolyspora erythraea. Furthermore, on the other side of the nok gene cluster was the nok $X$ gene, encoding a transmembrane efflux protein from the major facilitator superfamily, similar to the chloramphenicol resistance protein in Saccharopolyspora erythraea.

During our work to provide in vitro functional evidence for and biochemical characterization of our gene cluster, Kim et al. reported an ink gene cluster designated solely for K-252a biosynthesis, where a sequence of $20.3 \mathrm{~kb}$ was deposited in
GenBank.$^{35}$ We found, however, many striking discrepancies between the ink gene cluster and the nok gene cluster in both results and methods (see Fig. 2 and Table 1). Most notably, both of the two key genes (nokP and nokK) responsible for the formation of the modified dihydrostreptose were absent in the ink gene cluster. In addition, in the ink cluster the inkP gene, corresponding to $n o k C$, was found to lack 807 bp at its $3^{\prime}$-end, leading to a truncated gene (423 bp) fused with a small fragment (105 bp) of miscellaneous sequence. The resulting fused protein of InkP (175 a.a.) is shorter than NokC (409 a.a.), whereas NokC in sequence reasonably resembles its homologs, RebP (397 a.a) and StaP (417 a.a.), in rebeccamycin and staurosporine biosyntheses, respectively., ${ }^{9,19}$ Importantly, NokC is a cytochrome P450 enzyme that is indispensable for the biosynthesis of K-252a aglycone, K-252c. ${ }^{9,19,20}$ Similarly, in the ink cluster a 226 bp-segment in $5^{\prime}$-end of inkA (corresponding to nokF) is composed of other DNA. As compared to the nok cluster, several critical genes presumably involved in K-252a regulation and sresistance were absent or in different order in ink gene cluster, whereas most of them lacked sequence information. Specifically, downstream of nokC there appeared a great discrepancy between nok and ink in organization and function of genes, as shown in Fig. 2. Within this region of $c a .15 .6 \mathrm{~kb}$ (see nok orfs 25 35) were located the genes coding for a transcriptional activator (NokE), two-component system regulators (NokS and NokT) and transporters (NokV and NokW), presumably critical in the regulation and resistance of $\mathrm{K}-252 \mathrm{a}$ or its analogs. On the other (left) side $(c a .8 .8 \mathrm{~kb})$ of the gene cluster there was also found a major difference between the two gene clusters (Fig. 2). Notably, both sides (ca. $24 \mathrm{~kb}$ in total) of the ink cluster completely lacked sequence information. For more detailed comparison between nok and ink, see Table S1 in ESI. $\dagger$

\section{Comparison with biosynthetic gene clusters of rebeccamycin, staurosporine, AT2433 and violacein}

K-252a carries a special furanose moiety cross-bridged with the aglycone $(\mathrm{K}-252 \mathrm{c}, \mathbf{1})$ by catalytic actions of the cytochrome p450 enzyme (NokJ) and the N-Gtf (NokL), both of which were also found to be encoded as staN and staG, respectively, in the sta gene cluster for staurosporine biosynthesis. ${ }^{9}$ StaG utilizes the same aglycone $(\mathrm{K}-252 \mathrm{c}, \mathbf{1})$ as the recipient substrate, but incorporates an amino-pyranose moiety into staurosporine. Similar to the catalytic relationship between NokL and StaG, NokJ and StaN would have evolved, albeit with high sequence homology (51.0\% identity and $55.3 \%$ identity, respectively), to accept different sugar-attached aglycones for oxidative $\mathrm{C}-\mathrm{N}$ coupling. Hence, like StaN and StaG, NokJ and NokL act as important catalytic partners, indispensible for the synthesis of the bridged form of indolocarbazole glycosides. In particular, NokJ and NokL may serve as excellent targets and tools for protein engineering in the combinatorial biosynthesis of $\mathrm{K}-252 \mathrm{a}$ analogs. Interestingly, in nok and sta gene clusters the coding genes for these two enzymes were arranged in the same order and adjacent to those of aglycone biosynthesis (see Fig. 3). In fact, nokGFJLAB genes greatly resemble their 
homologous genes, staBANGOD, in genetic organization (gene order) of the gene clusters. ${ }^{45}$ In the senses of genetics and natural product chemistry, it would be reasonable to speculate that the two clusters, nok and sta, may be closely related in evolutionary relationship, as compared to the only other known gene clusters of indolocarbazole glycosides, reb and atm, for rebeccamycin and AT2433 biosyntheses, respectively.

Another interesting finding comes from the fact that, among the four genes (e.g. nokABCD in nok) required for aglycone biosynthesis, the genes coding for L-amino acid (LAA) oxidase and chromopyrrolic acid (CPA) synthase were found to be intimately coupled in gene order for nok, sta, reb and atm clusters (Fig. 3) and shared high sequence homology in amino acid (63.2-68.3\% similarity to nokA and 58.8-61.8\% similarity to $n o k B)$. Most notably, the vio gene cluster bears only two out of the four genes, i.e. vio $A$ and vio $B$, indispensible for violacein biosynthesis. ${ }^{46,47}$ The finding may be closely associated with the observation, as described in the companion paper, ${ }^{48}$ that the enzymatic product of LAA oxidase (NokA) was highly unstable and required CPA synthase (NokB) for immediate, efficient formation of CPA 3.

The other two genes, nokD and nokC, highly resemble $\operatorname{staC}(71.0 \%$ similarity and $60.8 \%$ identity) and staP $(58.9 \%$ similarity and $49.0 \%$ identity), respectively, in amino acid sequence, and were proposed to be responsible for the conversion of CPA to K-252c, the common aglycone core of K-252a and staurosporine. ${ }^{9}$ Interestingly, the reb and atm gene clusters also harbor the paired genes (rebC/rebP and atm $C /$ atm $P$, respectively) homologous to nokD/nokC, whereas both $\mathrm{rebC} / \mathrm{rebP}$ and atm $\mathrm{C} / \mathrm{atm} P$ were, however, responsible for the turnover of CPA to arcyriaflavin A, the common aglycone core of rebeccamycin and AT2433 (Fig. 1). ${ }^{19,20}$ Recent studies showed that the cytochrome p450 enzyme, encoded by staP, alone was able to convert CPA to both K-252c and arcyriaflavin A, whereas StaC (FAD monooxygenase) specifically directed the conversion to K-252c only and RebC to arcyriaflavin A. ${ }^{49}$ Notably, the nokD, staC, rebC and atm $C$ genes shared a similar degree of overall sequence similarity $(\sim 70 \%)$ and identity $(\sim 60 \%)$, whereas the nokC, staP, rebP and atmP genes also highly resemble each other in amino acid sequence $(60 \sim 70 \%$ similarity and $50 \sim 60 \%$ identity). Therefore, it would be a particularly intriguing subject of study to resolve the mechanistic difference between the apparently different types (NokD/StaC and RebC/StaC) of FAD monooxygenase. The finding of nokD/nokC genes from this study may thus provide useful addition to solving the mechanistic puzzle.

Moreover, for all the four gene clusters (nok, sta, reb and $a t m$ ) the transcriptional activator genes (nokE, staR, rebR and $a t m R$, respectively) were found to be conserved with good overall sequence homology $(41.9-45.6 \%$ similarity and $28.9-33.8 \%$ identity to $n o k E$ ), indicating the essential role of the genes for precise regulation of the gene clusters. In addition, in the nok cluster a AraC family transcriptional regulator gene (nokO) was revealed that was similar to the $n a n R 4$ found in the nanchangmycin gene cluster, ${ }^{50}$ which however did not show obvious similarity to the genes of other indolocarbazole gene clusters. Nevertheless, the nokX gene showed only low sequence homology, in regards to amino acid sequence $(33.8 \%$ similarity and $18.8 \%$ identity), to rebT ( similar to $\mathrm{atmI}$ ), which has been previously demonstrated to be responsible for rebeccamycin resistance, presumably through the aid of transmembrane electrochemical gradients. ${ }^{19}$

\section{In vitro functional characterization of K-252c biosynthesis}

Thus far, the enzymes of K-252a biosynthesis have not been functionally characterized in vitro and at the enzyme level. In particular, development of an in vitro or in vivo E. coli heterologous production system would be valuable, albeit challenging, for the facile and efficient production of K-252a or its biosynthetic intermediates. In light of this prospect and also to functionally characterize our gene cluster for K-252a or its analogs, we proceeded to examine the heterologous expression and functional characterization of the key enzymes involved in $\mathrm{K}-252 \mathrm{c}$ biosynthesis. To achieve the goal, a co-expression plasmid (pCY20) harboring nok $A B C D$ genes was constructed under the control of a common $\mathrm{T} 7$ promoter and a single $\mathrm{T} 7$ terminator to investigate the heterologous co-expression of the $\mathrm{K}-252 \mathrm{c}$ biosynthetic genes in E. coli (Fig. 6). Hence, we cloned each of nok $A B C D$ genes by PCR amplifications on the pJC3B5 fosmid as a template. PCR-amplified fragments of nok $A, \operatorname{nok} B$, nokC and nokD were then cloned into pET21b expression vectors with $N d e I$ and NheI sites to generate the non-His-tag expression plasmids, pJZ22, pJZ23, pCY10 and pCY5, respectively. Subsequently, the XbaI and EcoRI digestion fragment (with nokB) of pJZ23 was subcloned into pJZ22 (with nokA) within NheI and EcoRI sites. Repeated procedures were applied to clone nokC and nokD sequentially from pCY 10 and pCY5, respectively, into the resulting plasmid, thereby generating the nok $A B C D$ expression cassette, pCY20. In pCY20, the ribosomal binding site of each gene was preserved for expression. This construct will be useful for the additional cloning of more functional genes, e.g., N-glycosyltransferase genes and NDP-sugar biosynthetic genes, into the NheI and EcoRI sites for combinatorial modifications of K-252c, 1, to generate various glycosylated indolocarbazoles in E. coli.

Two approaches could be adapted to investigate the functional expression of the nokABCD cassette (pCY20) in the heterologous host $E$. coli, one being the in vitro (cell-free) tandem enzymatic reactions of NokABCD and the other being the in vivo biotransformation with $E$. coli harboring nok $A B C D$ genes. Because of the generally high $\mathrm{G}+\mathrm{C}$ content ( $>70 \%$ ) of actinomycete genes, their heterologous expression (in vitro) and subsequent biotransformation (in vivo) experiments would be expected to be challenging. To accomplish the functional characterization, we pursued the cell-free tandem enzymatic synthesis of K-252c by in vitro functional expression of the nok $A B C D$ gene cassette in E. coli as a first attempt. Hence, the nok $A B C D$ expression plasmid (pCY20, Fig. 6) was transformed into $E$. coli BL21 (DE3) cells. As a consequence, the co-expression of the four biosynthetic genes resulted, as expected, in insoluble aggregates of NokA, NokB and NokD, and poor expression of NokC, even with lowering the induction temperature to $15{ }^{\circ} \mathrm{C}$ and prolonging the IPTG-induction time. To improve the expression, we 


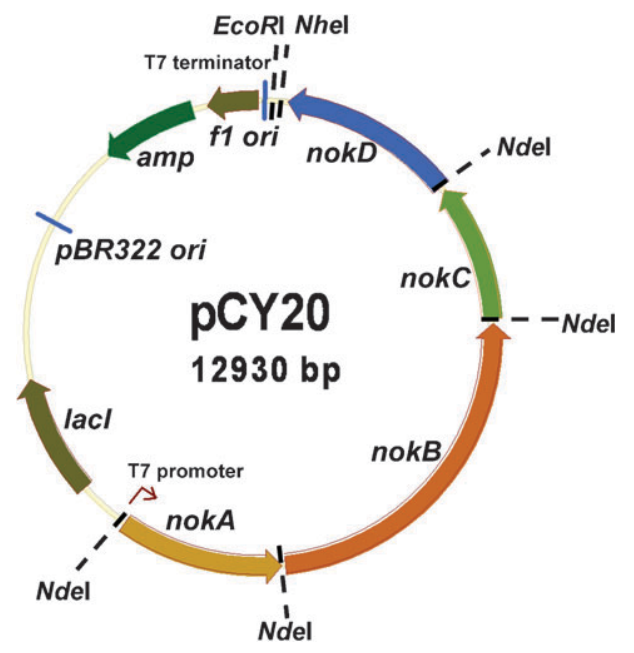

Fig. 6 The expression construct encoding the NokABCD proteins.

subsequently carried out the expression in E. coli of pCY20 with a combination of chaperones (GroEL, GroES, DnaK, DnaJ, and GrpE) encoded by pG-KJE7. ${ }^{51}$ However, the expression of the chaperone proteins troubled the SDS-PAGE analysis of the NokABCD proteins, because the chaperone proteins shared similar molecular weights with NokA and NokD. To accurately assess the optimal co-expression condition for pCY20, we hence cloned, expressed and purified each of the His-tagged proteins of NokA (54.7 kDa), NokB (112.0 kDa), NokC (45.4 kDa) and NokD (57.8 kDa), and therein screened for a common, suitable expression condition under co-expression with the chaperone teams encoded by pG-KJE7 (see ESI $\dagger$ ). The best, compromised condition for co-expression of the NokABCD proteins in the presence of the chaperones was finally set to be $250 \mu \mathrm{M}$ IPTG, $0.2 \%(\mathrm{w} / \mathrm{v})$ L-arabinose, $25{ }^{\circ} \mathrm{C}$ and $10 \mathrm{~h}$ for induction, leading to a sufficient quantity of soluble protein for each of the NokABCD proteins as analyzed in Fig. 7. Therefore, the cell-free crude extract of the NokABCD proteins was further utilized for enzymatic assays.

Subsequently, the cell-free crude extract of NokABCD was incubated with the presumed substrate, L-tryptophan (L-Trp, 2). As a result, RP-HPLC analysis of the reaction mixture revealed the formation of a new, major product (retention time $35.4 \mathrm{~min}$ ), as shown in Fig. 8 (see profiles $\mathrm{C}$ and D). The new product was subsequently prepared at a large scale, where the ethyl acetate extract of the reaction mixture was subjected to purification by semi-preparative RP-HPLC. Extensive NMR analyses by ${ }^{1} \mathrm{H}-\mathrm{NMR}$ (Fig. 9), ${ }^{13} \mathrm{C}-\mathrm{NMR}$ and $2 \mathrm{D}-\mathrm{NMR}$ (gCOSY and gHMQC) suggested the product to be chromopyrrolic acid (CPA, 3), the proposed enzyme product of NokB. Furthermore, high resolution ESI-MS analysis of the product revealed $[\mathrm{M}+\mathrm{H}]^{+}$at $m / z 386.232$ and $[\mathrm{M}+\mathrm{Na}]^{+}$at $m / z 408.237$ (Fig. 9), thereby confirming the product to be CPA $\left(\mathrm{C}_{22} \mathrm{H}_{15} \mathrm{~N}_{3} \mathrm{O}_{4}[\mathrm{M}+\mathrm{H}]^{+}\right.$, calcd. M.W. 386.114; $\mathrm{C}_{22} \mathrm{H}_{15} \mathrm{~N}_{3} \mathrm{O}_{4}[\mathrm{M}+\mathrm{Na}]^{+}$, calcd. M.W. 408.097). The observation may suggest that, despite producing sufficient soluble proteins of NokC and NokD, the cell-free extract of the E. coli expression system may not sufficiently support the catalytic action of NokC or NokD. This proposition was further

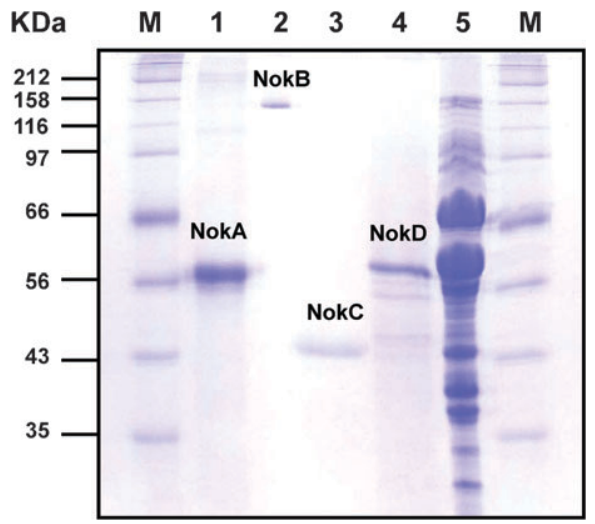

Fig. 7 SDS-PAGE analysis of the nokABCD expression. Purified His-tagged proteins of NokA (1), NokB (2), NokC (3) and NokD (4) from $E$. coli were subjected to SDS-PAGE as reference markers. (M) Molecular weight standards; (5) the cell-free crude extract of the NokABCD proteins.

supported by a recent observation by Howard-Jones and Walsh that in the staurosporine biosynthesis of StaP, a NokC homolog, the use of CPA as a substrate and exogenous addition of ferredoxin, flavodoxin $\mathrm{NADP}^{+}$-reductase and $\mathrm{NAD}(\mathrm{P}) \mathrm{H}$ was required to display StaP activity. ${ }^{49}$ Nevertheless, our experiments with the nok $A B C D$ expression cassette have clearly demonstrated the proposed functions and in vitro (cell-free) enzymatic activities of NokA and NokB involved in the biosynthetic pathway of $\mathrm{K}-252 \mathrm{a}$ and its analogs. And, the cell-free heterologous production of K-252c from E. coli could be possible, provided that the genes coding for the electron-transport components to support the NokC activity can be incorporated into the expression cassette.

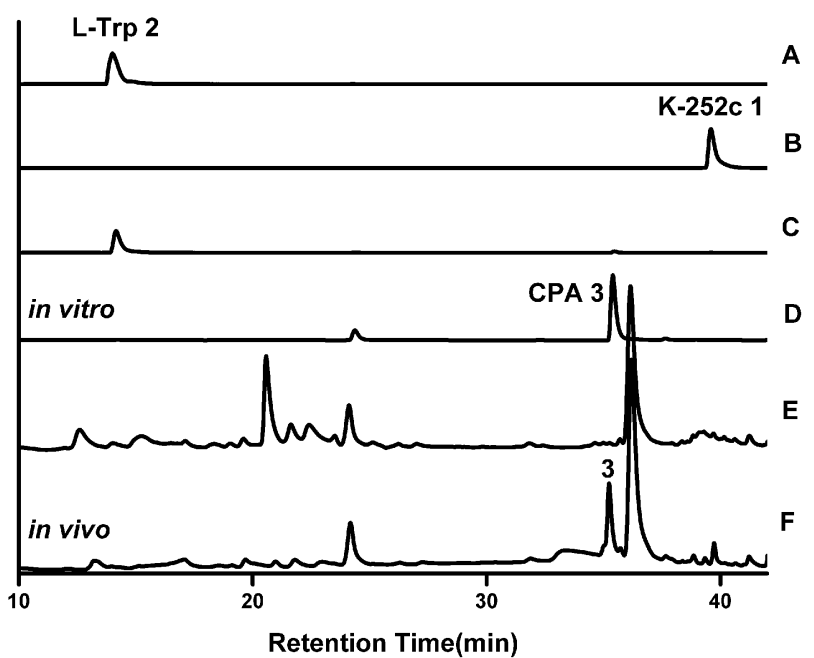

Fig. 8 RP-HPLC analysis of the in vivo and in vitro assays with NokABCD enzymes and L-tryptophan (L-Trp). The RP-HPLC analysis was monitored at $300 \mathrm{~nm}$. profile A: L-Trp standard; profile B: K-252c standard; profile C: the in vitro NokABCD reaction quenched at $0 \mathrm{~h}$; profile $\mathrm{D}$ : the in vitro NokABCD reaction quenched at $24 \mathrm{~h}$; profile $\mathrm{E}$ : the in vivo biotransformation control $(60 \mathrm{~h})$ with E. coli/pET21b; profile $\mathrm{F}$ : the in vivo biotransformation experiment $(60 \mathrm{~h})$ with $E$. coli/pCY20\&pG-KJE7. The in vitro reaction was conducted with the NokABCD cell-free crude extract, whereas the in vivo biotransformation with the $E$. coli cell culture fed with L-Trp. 


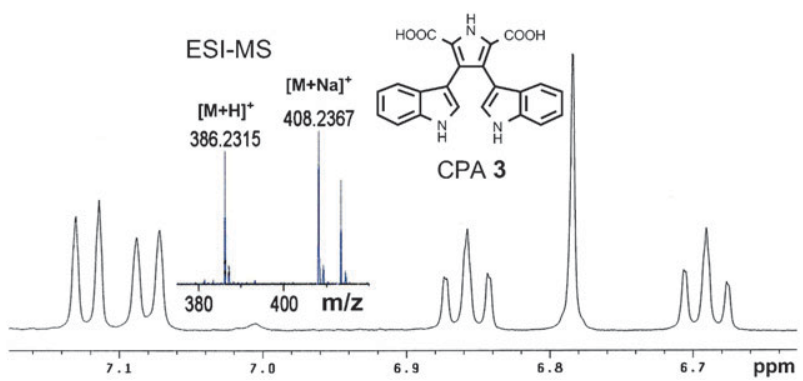

Fig. $9{ }^{1} \mathrm{H}-\mathrm{NMR}$ and high resolution ESI-MS of the chromopyrrolic acid (CPA) from the NokABCD reaction.

\section{In vivo isolation and production of chromopyrrlic acid from $E$. coli}

In light of successful cell-free enzymatic assays of NokABCD, we were prompted to investigate the possibility of utilizing the E. coli cells to produce CPA in vivo. Subsequently, the E. coli cells haboring pCY20 and pG-KJE7 were fed with L-Trp ( $0.4 \mathrm{~g}$ per litre of culture) when induced with $250 \mu \mathrm{M}$ IPTG and $0.1 \%(\mathrm{w} / \mathrm{v}) \mathrm{L}$-arabinose. After induction and incubation at $25{ }^{\circ} \mathrm{C}$ for $60 \mathrm{~h}$, the ethyl acetate extract of the culture broth was subjected to RP-HPLC analysis. Consequently, CPA 3 was detected as confirmed by co-elution with a CPA authentic standard (see profiles $\mathrm{E}$ and $\mathrm{F}$ in Fig. 8). Control experiments (without the nok $A B C D$ genes), however, did not give CPA, indicating that $\mathrm{CPA}$ was the direct product of in vivo NokABCD reactions. In addition, RP-HPLC analysis of cell-free crude extract of the $E$. coli cells from the biotransformation experiment found only a residual amount of CPA (data not shown), suggesting that the majority of CPA had been transported out the cells. The biotransformation experiment successfully demonstrated that the E. coli was capable of uptaking L-Trp and transporting CPA out as illustrated in Fig. 10. The in vivo biotransformation system may thus provide a useful platform for applications in facile production of CPA or related indolocarbazole compounds.

\section{Multi-functional roles of our gene cluster in Nocardiopsis sp. K-252}

Our K-252a gene cluster revealed two key genes, nokP (encoding hydroxylase/oxidase) and nokK (encoding carboxylate methyltransferase) that are indispensible for biosynthesis of K-252a, especially the dihydrostreptose moiety, in Nocardiopsis sp. K-252. This observation clearly suggests that the nok gene cluster is responsible for K-252a biosynthesis. Nonetheless, our companion paper revealed another important finding that NokL was capable of utilizing TDP-Rha as an alternative substrate to produce K-252d. ${ }^{48}$ Moreover, two distinct methyltransferase genes (nokK and $n o k M$ ) were disclosed within the nok gene cluster in this study. It should be noted that Yasuzawa et al. reported production of K-252a, K-252b, K-252c and K-252d in Nocardiopsis strains (Scheme 1). ${ }^{12}$ Together, these important findings led to a speculation that the nok gene cluster may encode not only for biosynthesis of K-252a but also for those of other indolocarbazole metabolites in this strain.

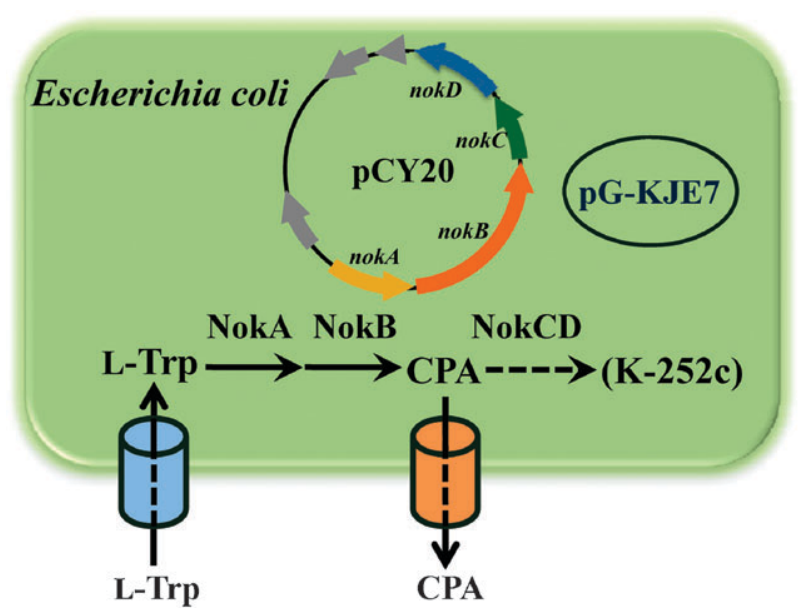

Fig. 10 Graphic representation of the in vivo biotransformation of L-tryptophan using E. coli harboring pCY20 and pG-KJE7.

Indeed, from our fosmid library clones we also identified genes, located elsewhere in the genome, coding for NDP-hexose 3,5-epimerase (Epi) and putative NDP-4-keto-rhamnose reductase (Kre) (data not shown), which may in principle work with nokF and nok $G$ of the gene cluster (or their homologous genes in the genome) to accomplish the biosynthesis of TDP-Rha in the strain (Scheme 1). On the other hand, another methyltransferase encoded by nokM may possibly be used for the biosynthesis of, yet unidentified, O-methylated K-252d (most likely $2^{\prime}$ - or $3^{\prime}$-O-methyl-K-252d) in the same strain, as $n o k M$ was found to share higher sequence similarity with spnI (a 2'- or $3^{\prime}-O$-methyltransferase gene) than $s p n K$ and $s p n H$ in methylation of spinosyn rhamnose. ${ }^{34,52}$ Based on our findings here and in the companion paper, we may thus postulate a more complete biosynthetic pathway, as illustrated in Scheme 1, to account for biosyntheses of indolocarbazole metabolites in Nocardiopsis sp. K-252. NokK can therefore carry out carboxylate methylation of K-252b to accomplish K-252a biosynthesis, whereas the biosynthesis of K-252d can also be satisfied by the substrate promiscuity of NokL revealed in the following paper.

\section{Materials and methods}

\section{Bacterial strains and culture conditions}

The Nocardiopsis sp. K-252 (NRRL15532, Nonomuraea longicatena $\mathrm{K}-252 \mathrm{~T}$ ) was obtained as a freeze-dried pellet from Agricultural Research Service Culture Collection (USA). The Nocardiopsis sp. K-252 was cultivated at $28^{\circ} \mathrm{C}, 250 \mathrm{rpm}$ in ISP medium 2 (yeast extract $0.4 \%$, malt extract $1 \%$, and glucose $0.4 \%, \mathrm{pH}$ at 7.3$)^{53}$ for approx. 6 to 7 days in baffled flasks for isolation of genomic DNA. The TransforMax EPI300 Escherichia coli (Epicentre) were used to construct genomic DNA library. The E. coli XL1-Blue and E. coli BL21-Codon Plus (DE3)-RP (Stratagene) served as hosts for routine subcloning and protein expression under standard culture conditions as described by Sambrook et al. ${ }^{54}$

\section{Plasmids and DNA manipulations}

The genomic DNA of Nocardiopsis sp. K-252 was extracted by Qiagen Genomic-tip system (Qiagen). The pCC1FOS vector 
(Epicentre) was employed for fosmid library construction. The pUC19 (NEB) and pBluescript $\mathrm{KS}^{+}$(Stratagene) were used to routinely clone restriction fragments for sequencing, whereas the pET21b and pET28a (Novagen) were used to overexpress genes. Restriction endonucleases and T4 DNA ligase were purchased from New England Biolabs (NEB). The $p f u$ DNA polymerase (Stratagene) was routinely utilized in polymerase chain reaction (PCR). The mini-preparation of DNA was performed on QIAprep spin miniprep kit (Qiagen). Unless specified otherwise, all chemicals were purchased from Sigma. Sequences of PCR primers are listed in Tables S2 and S3 $(\mathrm{ESI} \dagger)$.

\section{Probe design and PCR-screening for identification of the biosynthetic gene cluster for K-252a and its analogs}

The degenerate oligonucleotide primers (Operon Biotechnologies) were designed based on conserved regions of homologous genes of NDP-glucose synthase and NDP-glucose 4,6-dehydratase to give expected PCR-amplified fragments of $c a .300 \mathrm{bp}$ and $480 \mathrm{bp}$, respectively. For NDP-glucose synthase, primers were AG4 (forward) and AG5 (reverse); for NDP-glucose 4,6-dehydratase, primers were P1 (forward) and P2 (reverse). The PCR-amplified DNA fragments, as shown in Fig. S1 (ESI $\dagger$ ), were verified by sequencing, and then specific primers, dehy and syn, were designed based upon the resulting DNA sequences. Subsequently, the primer pairs (dehy and syn, Table S2 $\dagger$ ) were utilized as DNA probes to screen the fosmid library for identification of the biosynthetic gene cluster. The PCR (PTC-200 DNA Engine, MJ Research, USA) conditions were as follows: an initial denaturation $\left(5 \mathrm{~min}\right.$ at $\left.95{ }^{\circ} \mathrm{C}\right)$; 30 cycles of $1 \mathrm{~min}$ at $95^{\circ} \mathrm{C}, 1 \mathrm{~min}$ at $67^{\circ} \mathrm{C}$, and $1 \mathrm{~min}$ at $75^{\circ} \mathrm{C}$; and a final extension step of $10 \mathrm{~min}$ at $75^{\circ} \mathrm{C}$. Consequently, a PCR-positive fosmid clone, pJC3B5, was found. Furthermore, specific primers designed based upon $3^{\prime}$ and $5^{\prime}$ ends of pJC3B5 insert sequences were utilized for subsequent screening, leading to identification of two other fosmid clones, pJC28B7 and pJC40D7.

\section{DNA sequencing and ORF analysis}

The three overlapping fosmid clones, pJC3B5, pJC40D7 and pJC28B7, gave a DNA contig of $c a .57 \mathrm{~kb}$ in total. The BamHI and $S a c$ I restriction fragments of the fosmid clones with approx. 0.4 to $3 \mathrm{~kb}$ were subcloned into the cloning vectors for sequencing and assembling of a full-length fosmid contig spanning ca. $45 \mathrm{~kb}$ as shown in Fig. 3. ORF analysis was performed on Vector NTI program (InforMax), and the computer-aided database searching and sequence analysis were carried out using the BLAST server from the National Center for Biotechnology Information (NCBI, http://www.ncbi.nlm.nih.gov/BLAST).

\section{Nucleotide sequence accession number}

The complete sequence of our $45 \mathrm{~kb}$ genomic fragment harboring the entire biosynthetic gene cluster for K-252a and its analogs has been deposited in the GenBank under accession number FJ031030.

\section{Construction of NokA, NokB, NokC, NokD and NokABCD expression plasmids}

The K-252c biosynthetic genes, nok $A$, nokB, nokC and nokD, were amplified by PCR on pJC3B5 with the corresponding primers (Table S3) carrying NdeI and NheI restriction sites at the $5^{\prime}$ and $3^{\prime}$ ends, respectively. Each of the PCR-amplified gene fragments preserving the stop codon was individually cloned into the NdeI and NheI sites of pET21b to generate the resulting plasmids, pJZ22, pJZ23, pCY10 and pCY5, harboring nokA, nokB, nokC and nokD, respectively. To generate the expression plasmid encoding the biosynthesis of $\mathrm{K}-252 \mathrm{c}$, the coding genes (nok $A, \operatorname{nok} B, \operatorname{nok} C$ and nokD) were assembled in the same expression construct under the control of the same T7 promoter and a single T7 terminator. To do so, pJZ22 haboring nok $A$ served as a starting construct. After digestion of pJZ22 with NheI and EcoRI, the XbaI and EcoRI digestion fragment containing nokB from pJZ23 was ligated with the digested pJZ22 to generate pJZ25. Subsequently, nokC and nokD gene fragments flanked by $X b a \mathrm{I}$ and EcoRI from pCY10 and pCY5, respectively, were sequentially cloned into pJZ25 by the same method described above to generate the resulting plasmid pCY20.

\section{Heterologous co-expression of NokABCD in E. coli}

The expression construct, pCY20, was transformed into E. coli BL21 (DE3) for protein overexpression. For co-expression with the chaperone teams, pG-KJE7 was co-transformed into the same $E$ coli host. Transformants were cultured at $37{ }^{\circ} \mathrm{C}$ in Luria-Bertani (LB) medium with $100 \mu \mathrm{g} \mathrm{ml}^{-1}$ ampicillin and $30 \mu \mathrm{g} \mathrm{ml}^{-1}$ kanamycin until an $\mathrm{OD}_{600}$ of $0.4-0.5$ was reached. Subsequently, the culture was induced with $250 \mu \mathrm{M}$ isopropyl $\beta$-D-1-thiogalacto-pyranoside (IPTG) and $0.2 \% \quad(\mathrm{w} / \mathrm{v})$ L-arabinose at $25{ }^{\circ} \mathrm{C}$ for $10 \mathrm{~h}$. Cells were then harvested by centrifugation at $4{ }^{\circ} \mathrm{C}(1902 \mathrm{~g}, 20 \mathrm{~min})$ and subsequently disrupted by sonication at $4{ }^{\circ} \mathrm{C}$ in Tris buffer $(104 \mathrm{mM}$ Tris- $\mathrm{HCl}, 10 \%(\mathrm{v} / \mathrm{v})$ glycerol, $\mathrm{pH}$ 7.6). After centrifugation (15700 g, $20 \mathrm{~min})$ at $4{ }^{\circ} \mathrm{C}$ to remove cell debris, the cell-free crude extract was obtained for further experiments.

\section{RP-HPLC analyses of in vitro tandem enzymatic reactions of NokABCD}

The in vitro tandem NokABCD reactions were examined for production of possible biosynthetic intermediates or products. The reaction mixture in a total volume of $52 \mu$, containing $2 \mathrm{mM}$ substrate (L-tryptophan, L-Trp 2) and $40 \mu \mathrm{l}$ NokABCD cell-free crude extract in a reaction buffer $(80 \mathrm{mM}$ Tris- $\mathrm{HCl}$, $\mathrm{pH} 7.8,7.6 \%$ (v/v) glycerol), was incubated at $30{ }^{\circ} \mathrm{C}$ for $24 \mathrm{~h}$. The reaction was then terminated by an equal volume of ice-cold $\mathrm{MeOH}$. The reaction mixture was then analyzed by an ODS-C18 RP-HPLC analytical column $(4.6 \times 250 \mathrm{~mm}$, $5 \mu \mathrm{m}$, Zorbax, Agilent). HPLC analyses were performed by Agilent 1100 series equipped with quaternary pump and diode-array detector. The mobile phase for the HPLC elution consisted of methanol (solvent A), $2.5 \mathrm{mM}$ aqueous potassium phosphate at pH 3.5 (solvent B) and acetonitrile (solvent C). The reaction mixture was subjected to RP-HPLC analysis at a flow rate of $1.0 \mathrm{ml} \mathrm{min}{ }^{-1}$ with an elution gradient consisting of $8 \%$ solvent $\mathrm{A}$, as programmed as follows: $92 \%$ solvent $\mathrm{B}$ in 
5 min, $0-16 \%$ solvent $\mathrm{C}$ over $10 \mathrm{~min}, 16-28 \%$ solvent $\mathrm{C}$ over $15 \mathrm{~min}, 28-70 \%$ solvent $\mathrm{C}$ over $15 \mathrm{~min}, 70-80 \%$ solvent $\mathrm{C}$ over $2 \mathrm{~min}, 80 \%$ solvent $\mathrm{C}$ held for $5 \mathrm{~min}$, and then $80 \%$ to $0 \%$ solvent $\mathrm{C}$ over $3 \mathrm{~min}$. Finally, the column was equilibrated with $92 \%$ solvent $\mathrm{B}$ for $5 \mathrm{~min}$. The elution was monitored with a full-range of UV-vis wavelengths to trace all possible intermediates or products.

\section{Preparation and characterization of chromopyrrolic acid}

To prepare chromopyrrolic acid (CPA 3) from the NokA/NokB reactions, a reaction mixture $(104 \mu \mathrm{l})$ containing $4 \mathrm{mM}$ L-Trp 2, $30 \mathrm{mM}$ ammonium hydroxide, and $80 \mu \mathrm{l}$ cell-free crude extract of NokABCD in a reaction buffer (80 mM Tris- $\mathrm{HCl}, 7.6 \%$ (v/v) glycerol, $\mathrm{pH} 7.8$ ) was incubated at $30{ }^{\circ} \mathrm{C}$ for $24 \mathrm{~h}$. The reaction was quenched by an equal volume of ice-cold $\mathrm{MeOH}$. After centrifugation with microcon YM-10 (Millipore), the eluted mixture was adjusted to $\mathrm{pH} 3.0$ and extracted with ethyl acetate (EA), subsequently yielding crude CPA after removing EA. The crude CPA was further purified by a semi-preparative C18 RP-HPLC column (5C18-AR-I, $8.0 \times 250 \mathrm{~mm}, 5 \mu \mathrm{m}$, Cosmosil, Nacalai tesque, Japan) eluted with the mobile phase consisting of methanol (solvent A) and $2.5 \mathrm{mM}$ ammonium formate (solvent $\mathrm{B}$ ). The crude product, prepared from $13.5 \mathrm{ml}$ of reaction, was purified by using a HPLC gradient (flow rate at $3.0 \mathrm{ml} \mathrm{min} \mathrm{m}^{-1}$ ) programmed as follows: $15 \%$ solvent $\mathrm{A}$ in $5 \mathrm{~min}, 15-53 \%$ solvent A over $20 \mathrm{~min}, 53 \%$ solvent A held for $5 \mathrm{~min}, 53-80 \%$ solvent A over $3 \mathrm{~min}, 80 \%$ to $15 \%$ solvent A over $3 \mathrm{~min}$, and then $15 \%$ solvent $\mathrm{A}$ for $5 \mathrm{~min}$. The eluted product was neutralized to approximately $\mathrm{pH} 7.0$ by ammonium hydroxide, and then lyophilized to yield a white powder of CPA 3 (2.6 mg, ca. $99 \%$ purity as estimated by RP-HPLC analysis). The structural elucidation of the product was performed with NMR (Varian INOVA-500) and ESI-MS. ${ }^{1} \mathrm{H}-\mathrm{NMR}\left(\mathrm{CD}_{3} \mathrm{OD}\right.$, $500 \mathrm{MHz}), \delta_{\mathrm{H}} 6.691(2 \mathrm{H}, \mathrm{dd}, J=7.0 \mathrm{~Hz}), 6.785(2 \mathrm{H}, \mathrm{s}), 6.858$ $(2 \mathrm{H}, \mathrm{dd}, J=7.0 \mathrm{~Hz}), 7.080(2 \mathrm{H}, \mathrm{d}, J=8.0 \mathrm{~Hz})$, and 7.122 $(2 \mathrm{H}, \mathrm{d}, J=8.0 \mathrm{~Hz}) \mathrm{ppm} .{ }^{13} \mathrm{C}-\mathrm{NMR}\left(\mathrm{CD}_{3} \mathrm{OD}, 125 \mathrm{MHz}\right)$, $\delta_{\mathrm{C}} 110.236,111.671,119.328,121.107,121.504,125.252$, 125.847, 125.885, 129.374, 137.397, and $165.358 \mathrm{ppm}$. High resolution ESI-MS calculated for $\mathrm{C}_{22} \mathrm{H}_{15} \mathrm{~N}_{3} \mathrm{O}_{4}[\mathrm{M}+\mathrm{H}]^{+}$ 386.114; found 386.232; calculated for $\mathrm{C}_{22} \mathrm{H}_{15} \mathrm{~N}_{3} \mathrm{O}_{4}[\mathrm{M}+\mathrm{Na}]^{+}$ 408.097; found 408.237. The gCOSY and gHMQC 2D-NMR results are shown in Fig. $\mathrm{S} 2(\mathrm{ESI} \dagger)$.

\section{In vivo biotransformation experiments}

E. coli BL21 (DE3) co-transformants of pCY20 and pG-KJE7 were cultured and induced similarly as described. For in vivo biotransformation, $0.4 \mathrm{~g}$ of L-Trp was added into 11 culture of the $E$. coli upon induction, followed by additional growth at $25{ }^{\circ} \mathrm{C}$ for $60 \mathrm{~h}$. The culture was then added with hydrochloric acid to adjust the $\mathrm{pH}$ to 3.5. After centrifugation (1902 g, $15 \mathrm{~min}$ ), the culture broth was collected and extracted with EA. Upon evaporation of EA, the organic extract was subjected to RP-HPLC analysis for production of CPA as described. On the other hand, the cell pellet collected from centrifugation was washed with Tris buffer $(20 \mathrm{mM}$ Tris- $\mathrm{HCl}, \mathrm{pH}$ 7.6) and disrupted by French Press (two passages at 16000 psi, Spectronic Instruments). After centrifugation (15700 g, $1 \mathrm{~h})$, the cell debris was removed and the supernatant (soluble fraction) was examined for CPA production as described for the culture broth.

\section{Conclusions}

$\mathrm{K}-252 \mathrm{a}$ and its derivatives are promising neuroprotective and anticancer agents. In this study, we reported a complete sequence of a $45 \mathrm{~kb}$ Nocardiopsis $s p$. K-252 genomic fragment harboring the gene cluster for the biosynthesis of indolocarbazole metabolites in Nocardiopsis sp. K-252. The sequence containing 35 ORFs revealed several new, critical genes, e.g., nokK, nokP and nokEST genes, thus shedding new light on the biosynthesis, resistance and regulation of K-252a and its analogs. In addition, the gene cluster was in vitro functionally characterized, for the first time, in enzyme level. By constructing a heterologous co-expression system of E. coli, soluble proteins of NokABCD enzymes were successfully obtained for in vitro functional characterization, subsequently leading to production of chromopyrrolic acid (CPA) supporting $\mathrm{K}-252 \mathrm{c}$ biosynthesis. Furthermore, an in vivo biotransformation system with $E$. coli harboring nok $A B C D$ genes was established and readily afforded CPA in culture broth. Together with our results from the following paper, the findings of this study suggest that the gene cluster could be multifunctional to serve not only for biosynthesis of K-252a but also for those of other indolocarbazole metabolites (including K-252b, K-252c, K-252d and, yet unidentified, methylated K-252d) in Nocardiopsis sp. K-252, thus providing new insights into biosynthesis of the indolocarbazole family of antitumor antibiotics.

\section{Acknowledgements}

This research was supported by National Science Council (Taiwan) grants (NSC-91-2113-M-009-013 and NSC-922113-M-009-025) to Hsien-Tai Chiu. We thank HSP Research Institute (Kyoto Research Park, Japan) for kindly providing pG-KJE7 as a gift.

\section{References}

1 G. W. Gribble and S. J. Berthel, in Studies in Natural Products Chemistry, Elsevier, Amsterdam, 1993, pp. 365-409.

2 S. Akinaga, K. Sugiyama and T. Akiyama, Anti-Cancer Drug Des., $2000,15,43-52$.

3 M. Prudhomme, Eur. J. Med. Chem., 2003, 38, 123-140.

4 H. Nakano and S. Omura, J. Antibiot., 2009, 62, 17-26.

5 M. Prudhomme, Curr. Med. Chem.: Anti-Cancer Agents, 2004, 4, 509-521.

6 H. Kase, K. Iwahashi and Y. Matsuda, J. Antibiot., 1986, 39, $1059-1065$.

7 A. H. Ross, C. A. McKinnon, M. C. Daou, K. Ratliff and D. E. Wolf, J. Neurochem., 1995, 65, 2748-2756.

8 M. M. Berg, D. W. SternbergQll, L. F. Paradall and M. V. Chao, J. Biol. Chem., 1992, 267, 13-16.

9 H. Onaka, S. Taniguchi, Y. Igarashi and T. Furumai, J. Antibiot., 2002, 55, 1063-1071.

10 C. Rupprath, T. Schumacher and L. Elling, Curr. Med. Chem., 2005, 12, 1637-1675.

11 S. Nakanishi, Y. Matsuda, K. Iwahashi and H. Kase, J. Antibiot., 1986, 39, 1066-1071.

12 T. Yasuzawa, T. Iida, M. Yoshida, N. Hirayama, M. Takahashi, K. Shirahata and H. Sano, J. Antibiot., 1986, 39, 1072-1078. 
13 H. P. Wahl, U. Matern and H. Grisebach, Biochem. Biophys. Res. Commun., 1975, 64, 1041-1045.

14 J. Oh, S. G. Lee, B. G. Kim, J. K. Sohng, K. Liou and H. C. Lee, Biotechnol. Bioeng., 2003, 84, 452-458.

15 Y.-L. Chen, Y.-H. Chen, Y.-C. Lin, K.-C. Tsai and H.-T. Chiu, J. Biol. Chem., 2009, 284, 7352-7363.

16 C. Hyun, S. S. Kim, J. K. Sohng, J. Hahn, J. Kim and J. Suh, FEMS Microbiol. Lett., 2000, 183, 183-189.

17 H. Decker, S. Gaisser, S. Pelzer, P. Schneider, L. Westrich, W. Wohlleben and A. Bechthold, FEMS Microbiol. Lett., 1996, 141, 195-201.

18 Our $45 \mathrm{~kb}$ genomic sequence harboring the K-252a gene cluster has been deposited in GenBank under accession number: FJ031030.

19 C. Sánchez, I. A. Butovich, A. F. Braña, J. Rohr, C. Méndez and J. A. Salas, Chem. Biol., 2002, 9, 519-531.

20 Q. Gao, C. Zhang, S. Blanchard and J. S. Thorson, Chem. Biol., 2006, 13, 733-743.

21 H. Onaka, S. Asamizu, Y. Igarashi, R. Yoshida and T. Furumai, Biosci., Biotechnol., Biochem., 2005, 69, 1753-1759.

22 S. Nagano, J. R. Cupp-Vickery and T. L. Poulos, J. Biol. Chem., 2005, 280, 22102-22107.

23 M. C. Betlach, J. T. Kealey, G. W. Ashley and R. McDaniel, Biochemistry, 1998, 37, 14937-14942.

24 N. Parajuli, D. B. Basnet, H. Chan Lee, J. K. Sohng and K. Liou, Arch. Biochem. Biophys., 2004, 425, 233-241.

25 G. Draeger, S.-H. Park and H. G. Floss, J. Am. Chem. Soc., 1999, 121, 2611-2612.

26 X. He and H. W. Liu, Curr. Opin. Chem. Biol., 2002, 6, 590-597.

27 X. M. He and H. W. Liu, Annu. Rev. Biochem., 2002, 71, 701-754.

28 The deh gene was identified by PCR amplification using degenerate oligoprimers designed upon conserved regions of NDP-sugar 2,3-dehydratase homologs from various Streptomyces species (unpublished data). In 2,6-dideoxy-sugar biosynthesis, deh has often been found to couple with ker to achieve the 2-deoxygenation (ref. 25-27 and 33). Locating ker elsewhere in the genome of this strain is in progress. (NDP: nucleotide diphosphate)

29 K. Pissowotzki, K. Mansouri and W. Piepersberg, Mol. Gen. Genet., 1991, 231, 113-123.

30 G. L. Tang, Y. Q. Cheng and B. Shen, Chem. Biol., 2004, 11, 33-45.

31 L. Li, W. Deng, J. Song, W. Ding, Q. F. Zhao, C. Peng, W. W. Song, G. L. Tang and W. Liu, J. Bacteriol., 2008, 190, 251-263.

32 B. C. Kim, J. M. Lee, J. S. Ahn and B. S. Kim, J. Microbiol. Biotechnol., 2007, 17, 830-839.

33 A. Trefzer, J. A. Salas and A. Bechthold, Nat. Prod. Rep., 1999, 16, 283-299.
34 C. Waldron, P. Matsushima, P. R. Rosteck, Jr, M. C. Broughton, J. Turner, K. Madduri, K. P. Crawford, D. J. Merlo and R. H. Baltz, Chem. Biol., 2001, 8, 487-499.

35 S. Y. Kim, J. S. Park, C. S. Chae, C. G. Hyun, B. W. Choi, J. Shin and K. B. Oh, Appl. Microbiol. Biotechnol., 2007, 75, 1119-1126.

36 H. Yamase, L. S. Zhao and H. W. Liu, J. Am. Chem. Soc., 2000 122, 12397-12398.

37 K. Räty, J. Kantola, A. Hautala, J. Hakala, K. Ylihonko and P. Mäntsälä, Gene, 2002, 293, 115-122.

38 Z. Xu, K. Jakobi, K. Welzel and C. Hertweck, Chem. Biol., 2005, 12, 579-588.

39 R. M. Kagan and S. Clarke, Arch. Biochem. Biophys., 1994, 310, 417-427.

40 J. L. Martin and F. M. McMillan, Curr. Opin. Struct. Biol., 2002, 12, 783-793

41 S. Gullón, C. Olano, M. S. Abdelfattah, A. F. Braña, J. Rohr, C. Méndez and J. A. Salas, Appl. Environ. Microbiol., 2006, 72, $4172-4183$.

42 H. Onaka, S. Taniguchi, Y. Igarashi and T. Furumai, Biosci., Biotechnol., Biochem., 2003, 67, 127-138.

43 E. Mellado, L. M. Lorenzana, M. Rodríguez-Sáiz, B. Díez, P. Liras and J. L. Barredo, Microbiology (Reading, U. K.), 2002, 148, 1427-1438.

44 A. A. Khan, S. J. Kim, D. D. Paine and C. E. Cerniglia, Int. J. Syst. Evol. Microbiol., 2002, 52, 1997-2002.

45 C. L. Lu, Y. L. Huang, T. C. Wang and H.-T. Chiu, BMC Bioinf., 2006, 7, 295.

46 P. R. August, T. H. Grossman, C. Minor, M. P. Draper, I. A. MacNeil, J. M. Pemberton, K. M. Call, D. Holt and M. S. Osburne, J. Mol. Microbiol. Biotechnol., 2000, 2, 513-519.

47 R. V. Antônio and T. B. Creczynski-Pasa, Genet. Mol. Res., 2004, 3, 85-91.

48 H.-T. Chiu, Y.-C. Lin, M.-N. Lee, Y.-L. Chen, M.-S. Wang and C.-C. Lai, Mol. BioSyst., 2009, 5, DOI: 10.1039/B912395B, (the companion paper).

49 A. R. Howard-Jones and C. T. Walsh, J. Am. Chem. Soc., 2006, 128, 12289-12298.

50 Y. Sun, X. Zhou, H. Dong, G. Tu, M. Wang, B. Wang and Z. Deng, Chem. Biol., 2003, 10, 431-441.

51 K. Nishihara, M. Kanemori, M. Kitagawa, H. Yanagi and T. Yura, Appl. Environ. Microbiol., 1998, 64, 1694-1699.

52 S. Gaisser, R. Lill, G. Wirtz, F. Grolle, J. Staunton and P. F. Leadlay, Mol. Microbiol., 2001, 41, 1223-1231.

53 T. Kiser, M. Bibb, M. J. Buttner, K. F. Chater and D. A. Hopwood, in Practical Streptomyces Genetics, John Innes Foundation, Norwich, UK, 2000, pp. 117-118.

54 J. Sambrook and D. Russell, Molecular Cloning: A Laboratory Manual, Cold Spring Harbor Laboratory Press, New York, 2001. 